\title{
PENERAPAN DATA MINING ALGORITMA ASSOCIATION RULE METODE FP-GROWTH UNTUK MENGANALISA TINGKAT KEKERASAN DALAM RUMAH TANGGA (STUDI KASUS DI POLDA SUMATERA BARAT)
}

\author{
M.Hafizh \\ Teknik Informatika, Universitas Putra Indonesia "YPTK" Padang \\ email: hafizhmuhammad57@gmail.com
}

\begin{abstract}
Abstrak
Pada saat sekarang ini terus berkembang jumlah kasus Kekerasan Dalam Rumah Tangga (KDRT) sehingga membuat para penyidik ingin mendapatkan strategi penyidikan yang lebih baik. Dengan adanya strategi penyidikan yang benar dan cepat akan dapat mengurangi biaya dan mendapat sasaran yang tepat. Salah satu cara yang dapat dilakukan untuk penentuan strategi tersebut adalah dengan menggunakan teknik data mining. Adapun teknik yang digunakan dalam hal ini adalah Algoritma FP-Growth. FP-Growth adalah salah satu alternatif algoritma yang dapat digunakan untuk menentukan himpunan data yang paling sering muncul (frequent itemset) dalam sekumpulan data. Algoritma FP-Growth merupakan pengembangan dari algoritma Apriori. Sedangkan di dalam algoritma FP-Growth tidak dilakukan generate candidate karena FP-Growth menggunakan konsep pembangunan tree dalam pencarian frequent itemset. Penelitian dilakukan dengan mengamati beberapa variabel kasus KDRT yang sering dilaporkan, Yaitu Terlapor, Jenis Pekerjaan, dan jenis kekerasan yang dilakukan. Hasil penelitian ini adalah berupa suatu perangkat lunak dengan mengimplementasikan algoritma FP-Growth yang menggunakan konsep pembangunan FP-Tree dalam mencari Frequent Itemset.
\end{abstract}

Kata kunci : Data Mining, Association Rules, FP-Growth, Frequent Itemset

\section{Pendahuluan}

\subsection{Latar Belakang}

Perkembangan zaman berdampak pada perkembangan masyarakat, perilaku, maupun pergeseran budaya. Terjadinya peningkatan kepadatan penduduk, pengangguran bertambah, kemiskinan yang mengakibatkan tingginya angka kriminalitas terutama di daerah urban yang padat.

Salah satu tindakan kriminalitas adalah kekerasan yang terjadi dalam rumah tangga khususnya penganiayaan terhadap isteri merupakan salah satu penyebab kekacauan dalam masyarakat. (Menurut Rochmat Wahab, 2010) Kekerasan Dalam Rumah Tangga (KDRT) dapat diartikan sebagai tindakan kekerasan yang dilakukan oleh seorang pengasuh, orangtua, atau pasangan. KDRT dapat ditunjukkan dalam berbagai bentuk, di antaranya: Kekerasan fisik, penggunaan kekuatan fisik; kekerasan seksual, setiap aktivitas seksual yang dipaksakan; kekerasan emosional, tindakan yang mencakup ancaman, kritik dan menjatuhkan yang terjadi terus menerus; dan mengendalikan untuk memperoleh uang dan menggunakannya.

Association Rule Mining merupakan teknik yang ada pada Data Mining yang digunakan untuk menemukan pola assosiatif atau kombinasi dari item (Rana Rafsanzani dkk, 2014). Ada beberapa metode penemuan asosiasi yang sering digunakan antara lain Algoritma Apriori dan Algoritma FPGrowth (Donny Mitra Virgiawan dan Imam Mukhlash, 2013).

Dalam penelitian ini akan dilakukan pengujian apakah metode Association Rule Algoritma FP-Growth dapat digunakan untuk menyelesaikan permasalahan pada data Kekerasan Dalam Rumah Tangga (KDRT). Hasil dari penelitian ini diharapkan dapat memberikan informasi potensi KDRT 
yang dapat terjadi dan membantu pihak kepolisian dalam mengantisipasi kejahatan yang sering muncul.

\subsection{Perumusan Masalah}

Berdasarkan uraian latar belakang, maka penulis merumuskan suatu permasalahan yaitu sebagai berikut:

1. Bagaimana menganalisa tingkat KDRT untuk menemukan aturan assosiatif antara suatu kombinasi item dan membentuk pola kombinasi itemsets dengan menggunakan algoritma FPGrowth?

2. Bagaimana mengimplementasikan algoritma FP-Growth untuk menganalisa tingkat KDRT ?

3. Bagaimana faktor pendukung tersebut bisa dijadikan sebagai informasi dalam meningkatkan kewaspadaan masyarakat agar terhindar dari tindakan KDRT ?

\subsection{Batasan Masalah}

Agar penelitian tidak lepas dari latar belakang dan perumusan masalah, maka penulis membuat batasan masalahnya yaitu sebagai berikut :

1. Menggunakan Data Mining Association Rule untuk menghasilkan rules dan algoritma FPGrowth untuk menemukan pola kombinasi itemset

2. Data yang digunakan adalah data kekerasan dalam rumah tangga pada Polda Sumatera Barat.

3. Menggunakan aplikasi atau tools Data Mining WEKA sebagai pengujian hasil penelitian.

\section{Landasan Teori}

\subsection{Knowledge Discovery in Databases (KDD)}

Knowledge Discovery in Database (KDD) adalah proses menentukan informasi yang berguna serta pola-pola yang ada dalam data. Informasi ini terkandung dalam basis data yang berukuran besar yang sebelumnya tidak diketahui dan potensial bermanfaat. Data Mining merupakan salah satu langkah dari serangkaian proses iterative KDD (Ali Ikhwan dkk, 2014). Tahapan proses KDD dapat dilihat pada gambar 2.1.:

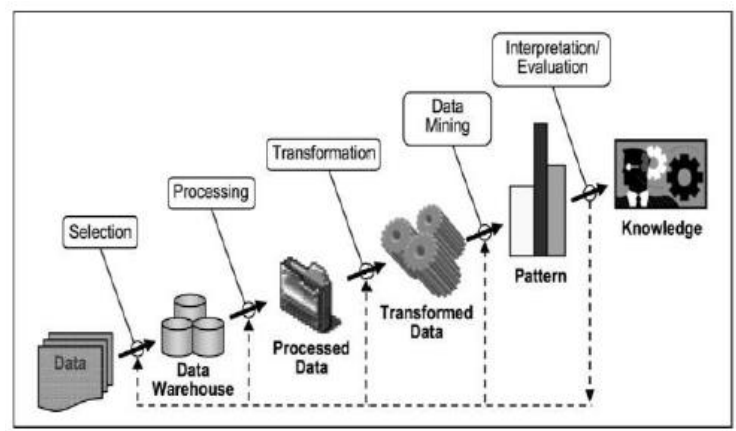

Gambar 2.1 Tahap-tahap KDD

\subsection{Data Mining}

Data Mining adalah proses menentukan pola dan informasi dari data yang berjumlah besar. Sumber data dapat berupa database, data warehouse, Web, tempat penyimpanan informasi lainnya atau data yang mengalir ke dalam sistem yang dinamis (Han et al, $2012: 8$ ).

\subsection{Association Rule}


Analisis asosiasi atau AssociationRrule Mining adalah teknik Data Mining untuk menemukan aturan asosiatif antara suatu kombinasi item. Algoritma aturan asosiasi akan menggunakan data latihan, sesuai dengan pengertian Data Mining, untuk menghasilkan pengetahuan.

\subsection{Algoritma FP-Growth}

Ririanti, 2014). FP-Growth adalah salah satu alternatif algoritma yang dapat digunakan untuk menentukan himpunan data yang paling sering muncul (frequent item set) dalam sekumpulan data. Algoritma FP-Growth merupakan pengembangan dari algoritma Apriori.

\section{Metode Penelitian}

\subsection{Kerangka Penelitian}

Penelitian merupakan suatu proses mencari sesuatu secara sistematis dalam waktu yang relatif lama dengan menggunakan metode ilmiah berdasarkan prosedur dan peraturan yang berlaku. Kegiatan penelitian memerlukan sebuah metodologi yang berisi kerangka pemikiran. Kerangka pemikiran merupakan gambaran dari langkah-langkah yang akan dilaksanakan agar penelitian dapat berjalan secara sistematis dan tujuan yang diharapkan dapat tercapai.

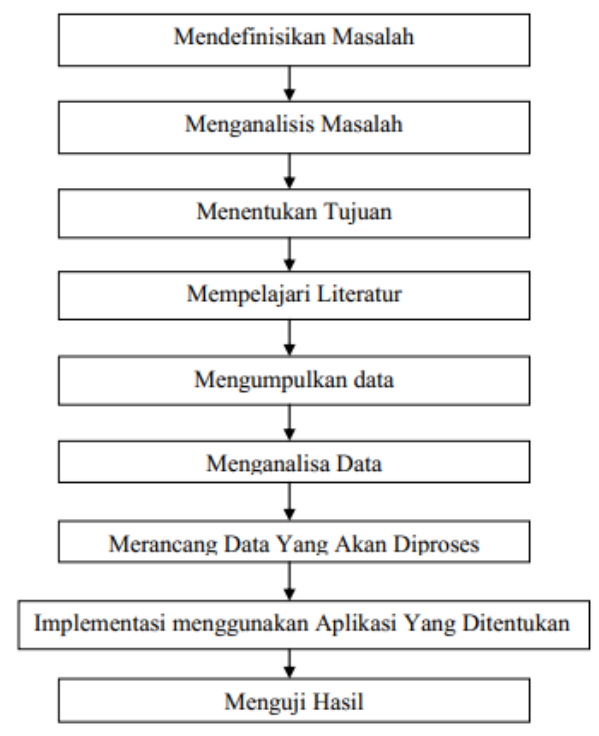

Gambar 3.1: Kerangka Penelitian

\subsection{TahapanPenelitian}

Ditahapan penelitian ini terdiri dari penelitian Mengidentifikasi Masalah, pengumpulan data,analisa, perancangan,implementasi dan pengujian.

\subsubsection{Mendefinisi Masalah}

Ruang lingkup masalah yang akan diteliti harus ditentukan terlebih dahulu, karena tanpa mampu menentukan serta mendefenisikan batasan masalah yang akan diteliti, maka tidak akan pernah didapat suatu solusi yang terbaik dari masalah tersebut. Jadi langkah pertama ini adalah langkah awal yang terpenting dalam penulisan ini. 


\subsubsection{Menganalisis Masalah}

Analisis masalah pada penelitian ini dilakukan dengan dua metode yaitu metode deskriptif dan metode komperatif.

\subsubsection{Menentukan Tujuan}

Berdasarkan pemahaman dari masalah, maka ditentukan tujuan yang akan dicapai dari penulisan ini. Pada tujuan ini ditentukan target yang dicapai, terutama yang dapat mengatasi masalah-masalah yang ada.

\subsubsection{Mempelajari Literature}

Untuk mencapai tujuan, maka dipelajari beberapa leiteratur-literatur yang diperkirakan dapat digunakan. Kemudian literatur-literaur yang dipelajari tersebut diseleksi untuk dapat ditentukan literatur-literatur mana yang akan digunakan dalam penelitian.

Literatur diambil dari internet, yang berupa artikel dan jurnal ilmiah tentang algoritma Apriori dan Data Mining, serta bahan bacaan lain yang mendukung penelitian.

\subsubsection{Mengumpulkan Data}

Dalam pengumpulan data dilakukan pemahaman tentang KDRT dan pengambilan data berupa informasi tindak kekerasan dalam rumah tangga (KDRT) pada Polda Sumatera Barat.

\subsubsection{Menganalisa Data}

Pada tahap ini data yang telah dikumpulkan akan dianalisis. Analisis menggunakan Association Rule yang dimaksud dilakukan melalui mekanisme penghitungan support dan confidence dari suatu hubungan item. Sebuah rule asosiasi dikatakan interesting jika nilai support adalah lebih besar dari minimum support dan juga nilai confidence adalah lebih besar dari minimum confidence .Dengan menggunakan teknik FP-Growth yang menghasilkan Frequent Itemset tanpa melakukan candidates generation. dengan tujuan untuk mendapatkan pengetahuan yang baru (knowledge) berupa informasi tentang tindakan KDRT yang kerap terjadi dewasa ini.

\subsubsection{Merancang Data Yang Akan Diproses}

Setelah menganalisa data secara manual maka dilakukan perancang informasi beerdasarkan data yang telah diproses tadi agar mempermudah dalam menentukan Frequent Itemset pada data KDRT.

\subsubsection{Implementasi Menggunakan Aplikasi Yang Ditentukan}

Setelah rancangan selesai dibuat, maka pada tahap ini dilakukan uji coba terhadap program tersebut sehingga analisis hasil implementasi dari pengujian model ini menggunakan WEKA sebagai aplikasinya. Jika penerapan sistem sudah berjalan dengan lancar, maka sistem dapat diimplementasikan sesuai dengan kebutuhan.

\subsubsection{Menguji Hasil}

Setelah implementasi dilakukan, maka pada tahap ini dilakukan pengujian untuk mengetahui hasil pengelompokkan data KDRT yang dibantu oleh sebuah softwere Data Mining yaitu WEKA.

\section{ANALISA DAN PERANCANGAN}




\subsection{Analisa Sistem}

Dalam penelitian ini tahapan metode Fp-Growthtersebut akan di curahkan pada data KDRT Polda Sumatera Barat berdasarkan laporan bulan Agustus sampai Desember 2015 khususnya wilayah Padang.

\subsection{Pengolahan Data}

\begin{tabular}{|c|c|c|c|}
\hline TID & ITEM & TID & ITEM \\
\hline 1 & K3 & 30 & K3 \\
\hline 2 & $\mathrm{C}, \mathrm{B}, \mathrm{K} 2$ & 31 & $\mathrm{C}, \mathrm{K} 2$ \\
\hline 3 & $\mathrm{C}, \mathrm{B}, \mathrm{K} 1$ & 32 & $\mathrm{~B}, \mathrm{~K} 1$ \\
\hline 4 & $\mathrm{~B}, \mathrm{~K} 3$ & 33 & $\mathrm{C}, \mathrm{B}, \mathrm{K} 1$ \\
\hline 5 & $\mathrm{~B}, \mathrm{~K} 3$ & 34 & $\mathrm{C}, \mathrm{B}, \mathrm{K} 2$ \\
\hline 6 & $\mathrm{C}, \mathrm{K} 1$ & 35 & $\mathrm{C}, \mathrm{K} 3$ \\
\hline 7 & $\mathrm{C}, \mathrm{B}, \mathrm{K} 1$ & 36 & $\mathrm{C}, \mathrm{B}, \mathrm{K} 3$ \\
\hline 8 & $\mathrm{~B}, \mathrm{~K} 2$ & 37 & $\mathrm{~B}, \mathrm{~K} 1$ \\
\hline 9 & K3 & 38 & $\mathrm{C}, \mathrm{B}, \mathrm{K} 1$ \\
\hline 10 & $\mathrm{C}, \mathrm{B}, \mathrm{K} 1$ & 39 & $\mathrm{~B}, \mathrm{~K} 1$ \\
\hline 11 & K1 & 40 & K1 \\
\hline 12 & $\mathrm{~B}, \mathrm{~K} 3$ & 41 & K1 \\
\hline 13 & $\mathrm{~B}, \mathrm{~K} 3$ & 42 & $\mathrm{C}, \mathrm{B}, \mathrm{K} 3$ \\
\hline 14 & K1 & 43 & $\mathrm{C}, \mathrm{B}, \mathrm{K} 2$ \\
\hline 15 & $\mathrm{~B}, \mathrm{~K} 1$ & 44 & $\mathrm{C}, \mathrm{B}, \mathrm{K} 3$ \\
\hline 16 & $\mathrm{C}, \mathrm{K} 1$ & 45 & $\mathrm{C}, \mathrm{B}, \mathrm{K} 3$ \\
\hline 17 & $\mathrm{C}, \mathrm{B}, \mathrm{K} 2$ & 46 & $\mathrm{~B}, \mathrm{~K} 1$ \\
\hline 18 & $\mathrm{C}, \mathrm{B}, \mathrm{K} 3$ & 47 & $\mathrm{C}, \mathrm{K} 2$ \\
\hline 19 & $\mathrm{C}, \mathrm{B}, \mathrm{K} 2$ & 48 & $\mathrm{~B}, \mathrm{~K} 3$ \\
\hline 20 & C,B,K1 & 49 & $\mathrm{C}, \mathrm{B}, \mathrm{K} 3$ \\
\hline 21 & $\mathrm{~B}, \mathrm{~K} 1$ & 50 & $\mathrm{~B}, \mathrm{~K} 3$ \\
\hline 22 & $\mathrm{~B}, \mathrm{~K} 1$ & 51 & $\mathrm{~B}, \mathrm{~K} 1$ \\
\hline 23 & $\mathrm{~B}, \mathrm{C}, \mathrm{K} 2$ & 52 & $\mathrm{C}, \mathrm{B}, \mathrm{K} 1$ \\
\hline 24 & $\mathrm{C}, \mathrm{B}, \mathrm{K} 3$ & 53 & $\mathrm{C}, \mathrm{K} 3$ \\
\hline 25 & $\mathrm{C}, \mathrm{B}, \mathrm{K} 1$ & 54 & $\mathrm{C}, \mathrm{B}, \mathrm{K} 1$ \\
\hline 26 & $\mathrm{C}, \mathrm{B}, \mathrm{K} 2$ & 55 & K3 \\
\hline 27 & $\mathrm{C}, \mathrm{B}, \mathrm{K} 2$ & 56 & $\mathrm{C}, \mathrm{K} 2$ \\
\hline 28 & $\mathrm{~B}, \mathrm{~K} 1$ & & \\
\hline 29 & $\mathrm{C}, \mathrm{B}, \mathrm{K} 1$ & & \\
\hline
\end{tabular}

Gambar 4.1: Data Kasus KDRT

Maka langkah selanjutnya adalah pembentukan Fp-Tree dengan melihat tabel.

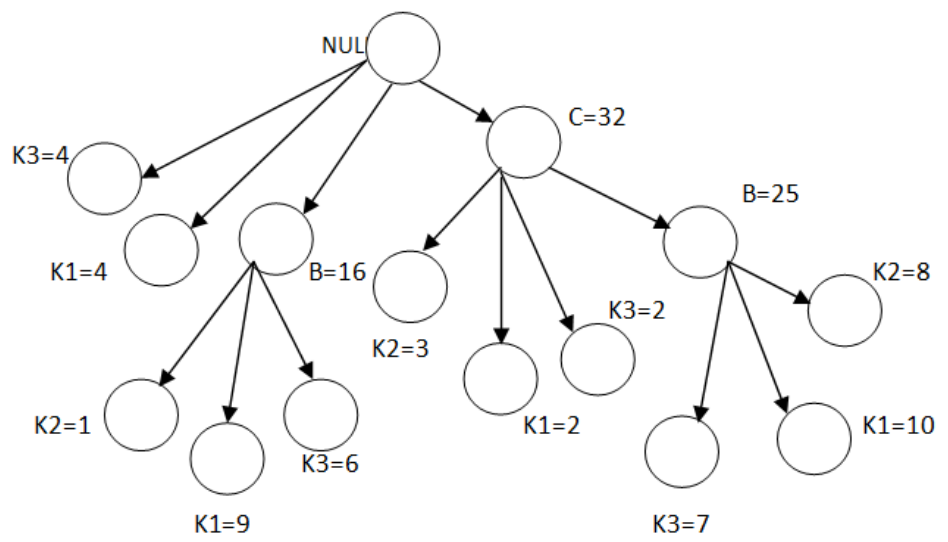

Gambar 4.5 Hasil Pembentukan Fp-Tree Setelah Pembacaan TID 56

Selanjutnya menghitung support dan confidence dari hasil pembentukan $f p$-tree yang sudah di lakukan. Rumus : 


$$
\begin{gathered}
\text { support }=\frac{\sum \text { jumlah Kasus }}{\sum \text { jumlah seluruh kasus }} \times 100 \% \\
\text { Confidence }=\frac{\sum \text { jumlah Kasus }}{\sum \text { Jumlah Kasus Pada Antecedent }} \times 100 \%
\end{gathered}
$$

Maka di dapatkan rule yang memiliki support $\geq 14 \%$ dan confidence $\geq 72 \%$ sebagai berikut :

Tabel 4.9: Hasil Rule

\begin{tabular}{|c|c|c|}
\hline If Antecedent then Consequent & Support & Confidence \\
\hline If Psikis (K2) Then Swasta (B) & $9 / 56=16 \%$ & $9 / 12=75 \%$ \\
\hline If Fisik (K1) Then Swasta (B) & $19 / 56=34 \%$ & $19 / 25=76 \%$ \\
\hline If Psikis (K2) Then Ibu Rumah Tangga (C) & $11 / 56=19 \%$ & $11 / 12=92 \%$ \\
\hline If Ibu Rumah Tangga (C) Then Swasta (B) & $25 / 56=45 \%$ & $25 / 32=78 \%$ \\
\hline If Swasta (B), Psikis (K2) Then Ibu Rumah Tangga(C) & $8 / 56=14 \%$ & $8 / 9=89 \%$ \\
\hline If Ibu Rumah Tangga(C), Fisik (K1) Then Swasta (B) & $10 / 56=18 \%$ & $10 / 12=83 \%$ \\
\hline If Ibu Rumah Tangga(C), Psikis (K2) Then Swasta (B) & $8 / 56=14 \%$ & $8 / 11=72 \%$ \\
\hline
\end{tabular}

\subsection{Implementasi}

pilih "Open file" dan silahkan masukkan datanya dan pilih open.

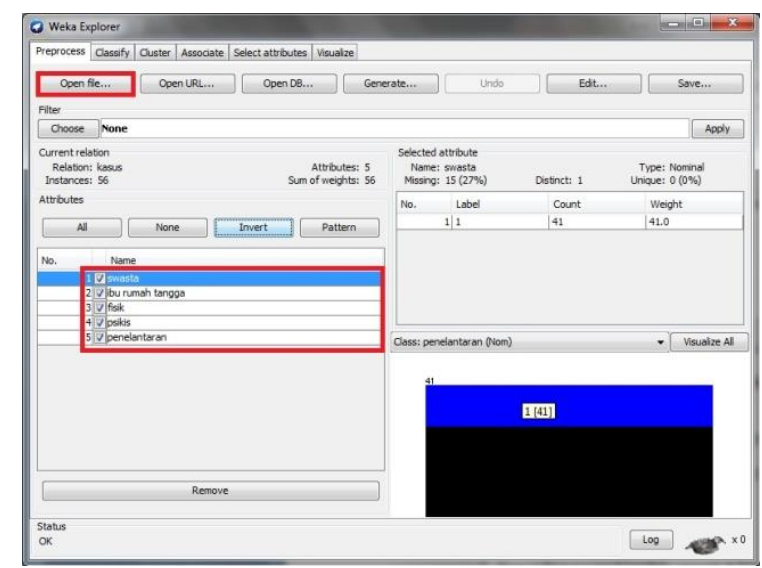

Gambar 5.1 Menginputkan Data 
Lakukan proses dengan memilih sub menu "Associate" dan pilih "Fp-growth" kemudian lakukan konfigurasi seperti di bawah ini :

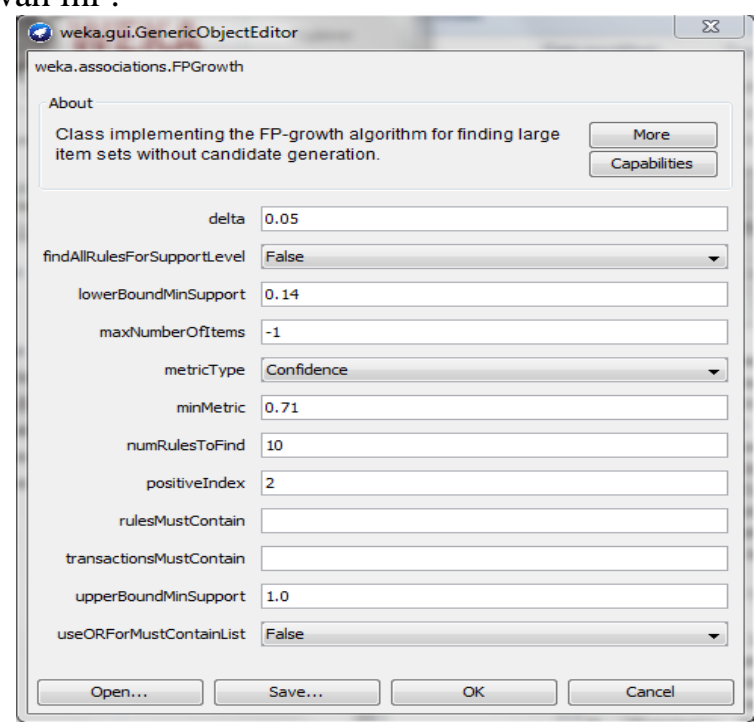

Gambar 5.2 Memulai Proses FP-Growth

setelah itu klik "Star" maka akan muncul hasil seperti di gambar 5.3.

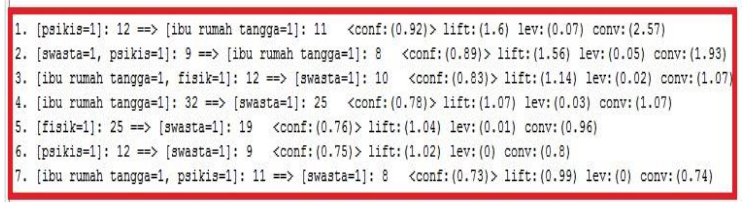

Gambar 5.3 Hasil Dari Proses Weka

Dari hasil di atas dapat dilihat bahwa rule yang didapat ada 7 yang memiliki nilai support $\geq 14 \%$ dan confidence $\geq 72 \%$, sama dengan pencarian manual yang dilakukan.

\section{Kesimpulan}

Berdasarkan hasil analisa dan pengujian yang telah dilakukan, maka dapat disimpulkan beberapa hal yang terkait dengan penelitian ini. Setelah dilakukan pengujian didapatkan beberapa hubungan antara terlapor laki-laki, jenis pekerjaan dan jenis kekerasan kasus KDRT menggunakan algoritma Association Rule metode FP-Growth. Adapun kesimpulan yang didapatkan sebagai berikut :

1. Metode FP-Growth dapat membantu mengelompokan variabel-variabel yang terdapat pada sebuah kasus serta menghasilkan suatu pengetahuan baru tentang kasus KDRT sehingga memudahkan proses penyidikan.

2. Pada penelitian ini adapun pengujian dengan nilai minimum support sebesar $12,5 \%$ dan minimum confidence 100\% terdapat 6 strong Association Rule dengan 1 strong Association Rule yang mempunyai kombinasi terbaik yaitu Jika Pekerjaan Pelaku Swasta, Korban Ibu Rumah tangga, Dengan Jenis Kekerasan Fisik Maka Jenis Kelamin Terlapor Laki-laki.

3. Dari pengujian data KDRT tahun 2015, maka diketahui bahwa pelaku laki-laki adalah pelaku yang paling sering melakukan tindakan KDRT di daerah Padang dengan tingkat kepercayaan (Nilai Confidence) sebesar 100\%.

\section{Referensi}


[1] Ali Ikhwan, Dicky Nofriansyah, Sriani. 2014. Penerapan Data Mining dengan Algoritma Fp-Growth untuk Mendukung Strategi Promosi Pendidikan ( Studi Kasus Kampus STMIK Triguna Dharma) Padang : Program Studi Sistem Komputer.

[2] Bharat Gupta. 2011. FP-Tree Based Algorithms Analysis: FPGrowth, COFI-Tree and CT-PRO. India : Student, Department of Computer Science Thapar University.

[3] David samuel. 2008. Penerapan Stuktur Fp-tree dan Algoritma Fp-growth Dalam Optimasi Penentuan Frequent Itemset. Bandung : Program Studi Teknik Informatika.

[4] Erwin. 2009. Analisis Market Basket Dengan AlgoritmaApriori dan FP-Growth. Sumatera Selatan : Program Studi Teknik Informatika, Fakultas Ilmu Komputer, Universitas Sriwijaya.

[5] Hamidah Abdurrachman. 2010. Perlindungan Hukum Terhadap Korban Kekerasan Dalam Rumah Tangga dalam Putusan Pengadilan Negeri Sebagai Implementasi Hak-Hak Korban. Jawa Tengah : Fakultas Hukum Universitas Pancasakti.

[6] Kennedi Tampubolon, Hoga Saragih, Bobby Reza. 2013. Implementasi Data Mining Algoritma Apriori Pada Sistem Persediaan Alat-alat Kesehatan. Medan : Program Pascasarjana STMIK ERESHA.

[7] Mujib Ridwan, Hadi Suyono, dan M. Sarosa. 2013. Penerapan Data Mining Untuk Evaluasi Kinerja Akademik Mahasiswa Menggunakan Algoritma Naive Bayes Classifier.

[8] Nurhayati. 2014. Metode Rough Set untuk Melihat Perilaku Suami yang Menjadi Akseptor KB Vasektomi. Binjai Sumut : Program Studi Teknik Informatika.

[9] Yuli Asriningtias, Rodhyah Mardhiyah. 2014. Aplikasi Data Mining Untuk Menampilkan Informasi Tingkat Kelulusan Mahasiswa. Yogyakarta : Program Studi Teknik Informatika.

[10] Ririanti. 2014. Implementasi Algoritma Fp-growth Pada Aplikasi Prediksi Persediaan Sepeda Motor (Studi Kasus PT. Pilar Deli Labumas).Medan : Mahasiswa Program Studi Teknik Informatika STMIK Budi Darma.

[11] Rana Rafsanzani, Candra Dewi, Dian Eka Ratnawati. 2014. Pencarian Association Rule Pada Data Pengguna Aplikasi Android Dengan Metode Fp-Growth. Jawa Timur : Program Studi Teknik Informatika, Program Teknologi Informasi dan Ilmu Komputer Universitas Brawijaya. 